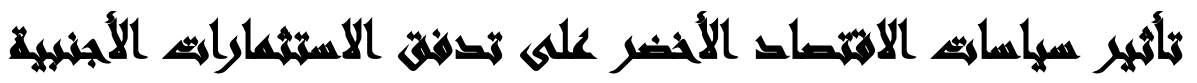

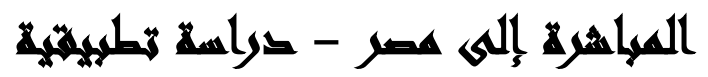

[19]

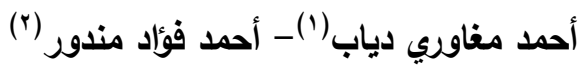

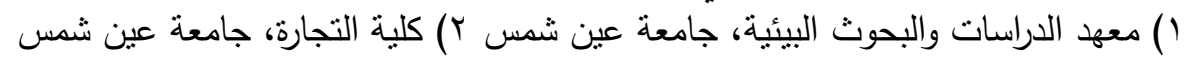

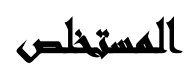

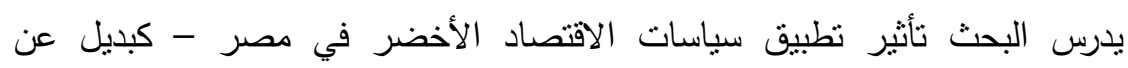

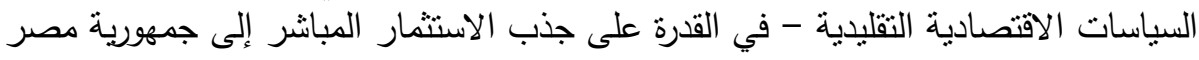

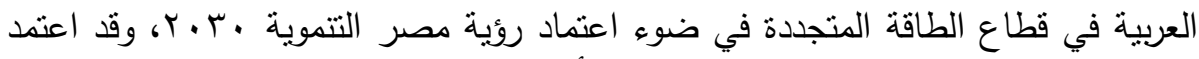

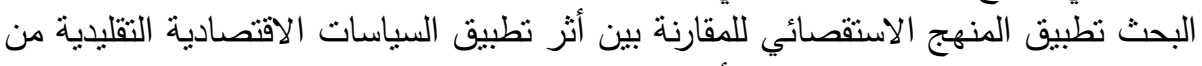

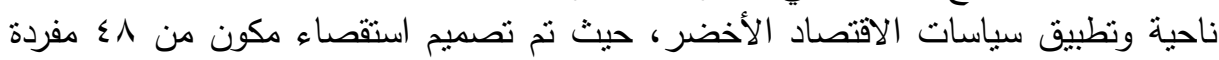

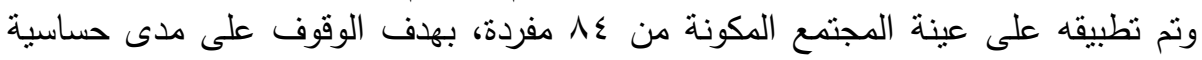

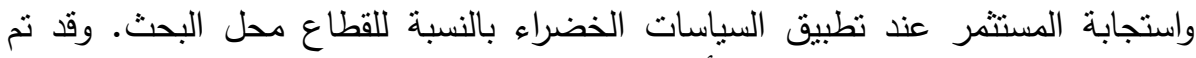

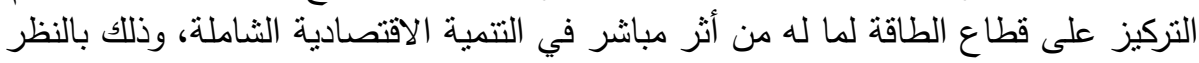

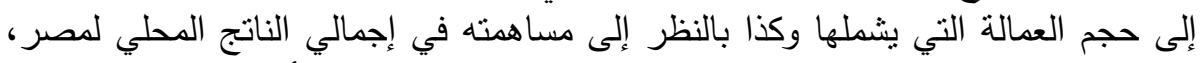

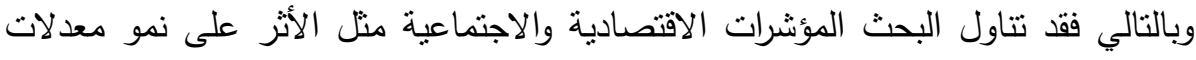

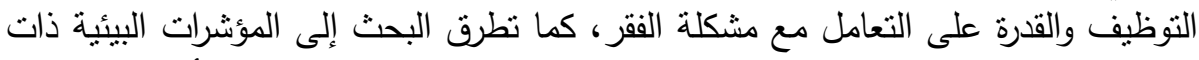

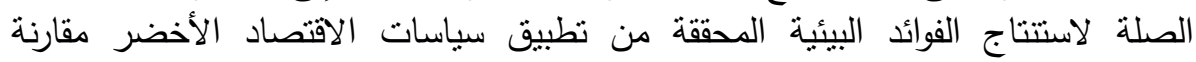

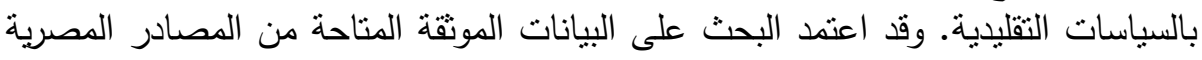

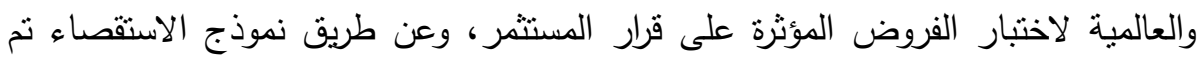

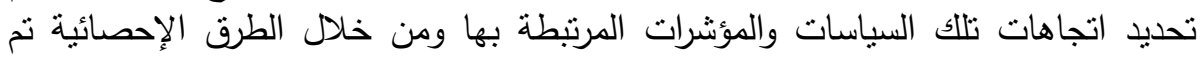

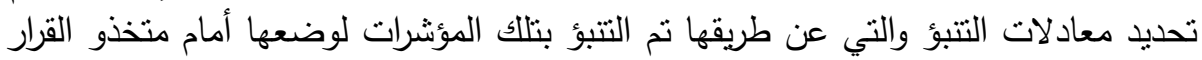

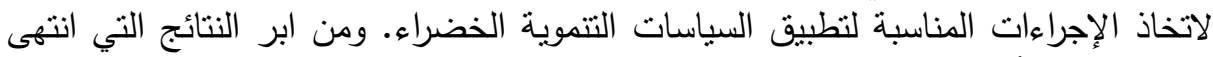

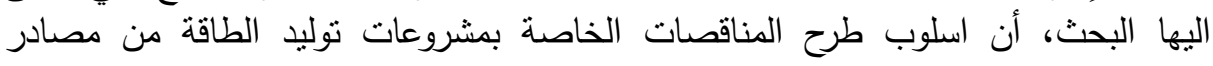

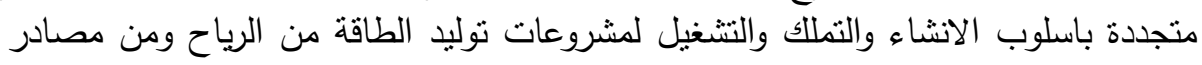

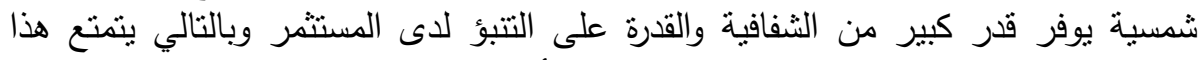

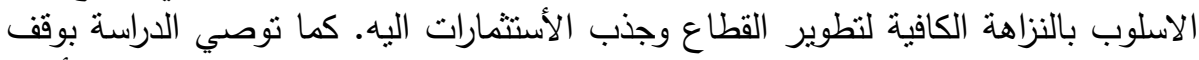

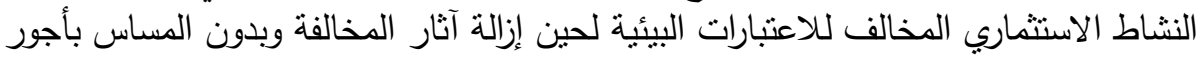

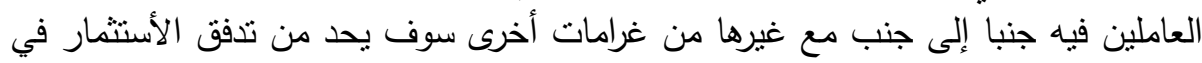

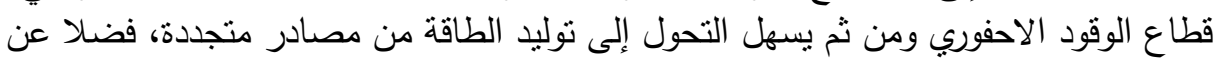

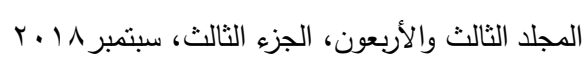




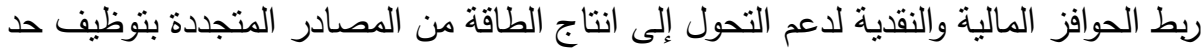

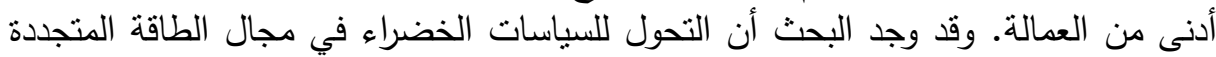

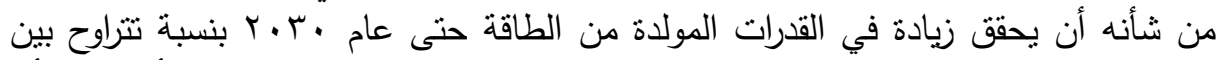

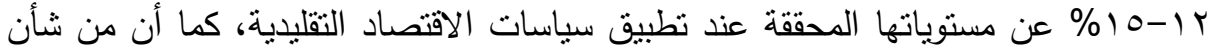

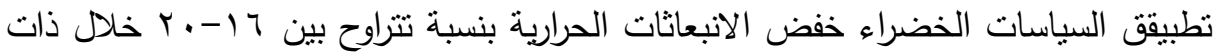
الفترة.

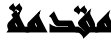

فطن العالم منذ عام 1992 إلي أهمية مفهوم البيئة المستدامة وذلك في مؤتمر قمة

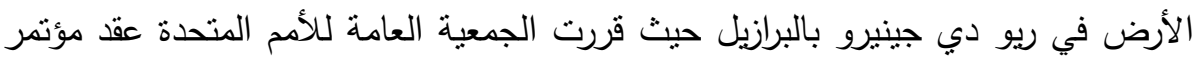

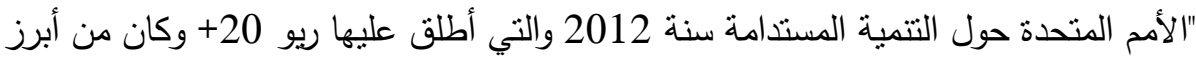
أهدافها : ضمان الالتزام السياسي للدول الأعضاء تجاه التتمية المستدامة، ومواجهة التحديات المانتة أمام الدول لتتفيذ هذا المفهوم. وفي هذا الإطار أصدر برنامج الأمم المتحدة للبيئة،

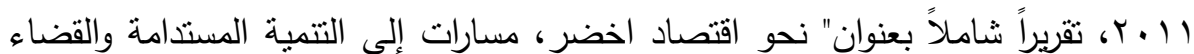
على الفقر" وهو التقرير الذي يعضد الحاجة الملحة لاستثمار 2\% من الناتج المحلي الإجمالي

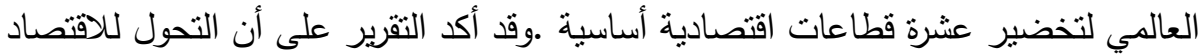
الأخضر من شأنه أن يحفز النشاط الاقتصادي مع تقلبل مخاطر الأزمات التي تزداد تأصلاً

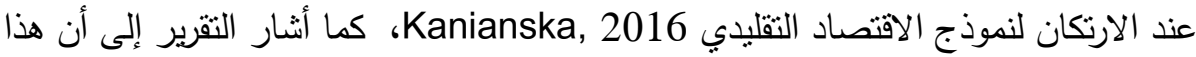

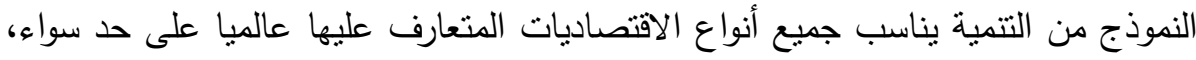

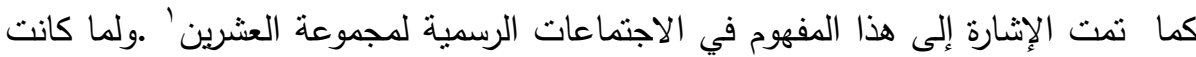

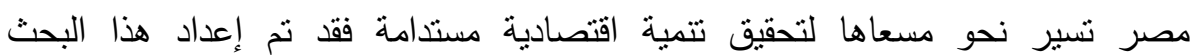

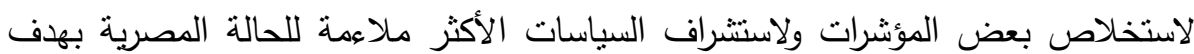

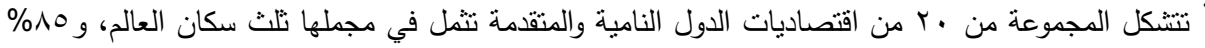

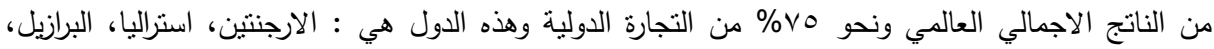

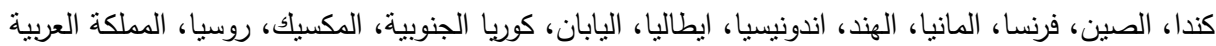

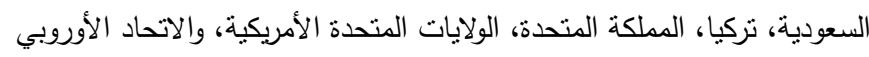

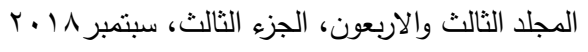


الخروج بنتائج للمساهمة في تطوير منظومة التتمية المستدامة والثاملة بالثكل الذي يتسق مع روية مصر 2030 .

\section{And 12 and}

يتعرض البحث إلى بعض المشكلات التي نواجه متخذي القرار الاستثماري في مصر سواء في شركات القطاع الخاص وكذا على مستوى المسئولين الحكوميين المنوط بهم اتخاذ القرارات والإجراءات وتتفيذ السياسات ذات الصلة بموضوع البحث، وذلك في ضوء نطبيق

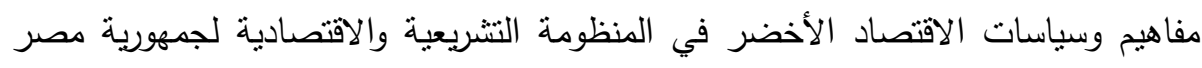
العربية .لذلك يتعرض البحث إلى التساؤل الجوهري الخاص بمدى إمكانية قيام متخذي القرار

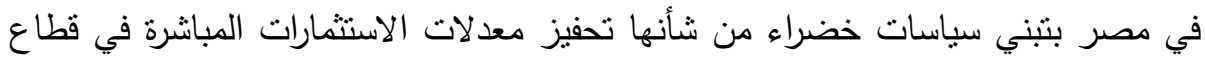
الطاقة المتجددة وما يترتب عليه من فرص توظيف والقضاء أو الحد من الفقر مع وجود إطار لحماية وإعادة تخصيص الموارد الطبيعية بالثكل الذي يحافظ على استخامتها ويحقق الفعالية في استخدامها سواء كانت هذه الموارد بشرية أو طبيعية.

وقد نطرقت التقرير الصادر عن برنامج الأمم المتحدة للبيئة عام UNEP, Y. V

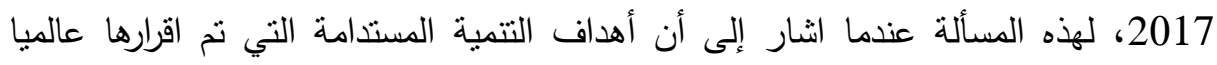
تشمل الاقرار بضرورة الانتباه للابعاد البيئة والاجتماعية عند التخطيط للتتمية الاقتصادية التهاه المستدامة، معتبرا أن التحديات التي تواجه متخذ القرار الاستثماري واسعة النطاق وتتطلب التباه

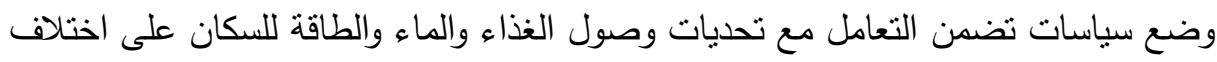

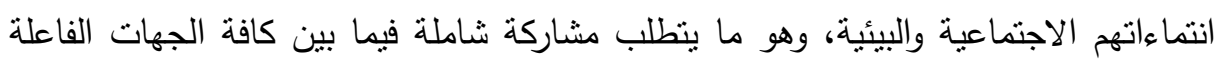

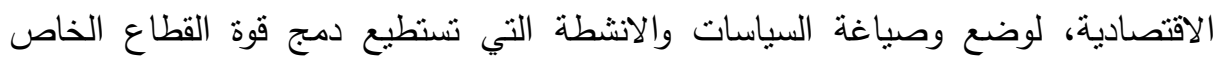
وإدراجها ضمن منظومة التتمية المستدامة.

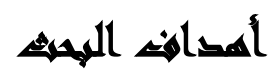

يكمن الهدف الرئيسي للبحث في دراسة نأثير سياسات الاقتصاد الأخضر على تدفق

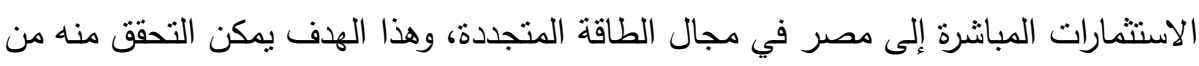

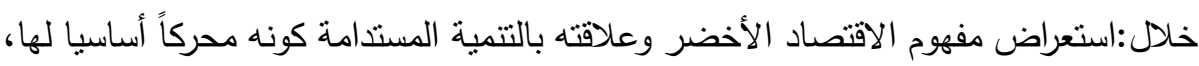

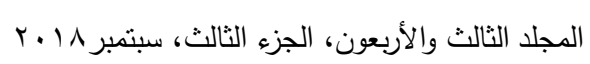


وليست بديلاً عنها، مع بيان مساهمة الاقتصاد الأخضر في التغلب على بعض المشكلات

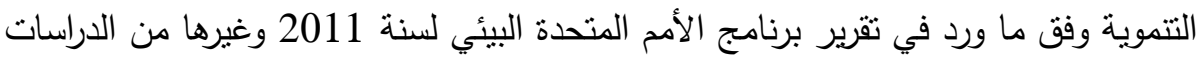

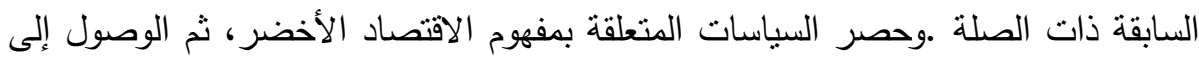
نتائج التحول إلى الاقتصاد الأخضر على صعيد تدفق الاستثمارات.

\section{أهميد المهيد}

ترتكز أهمية البحث في قدرته على تحديد السياسات التي يمكن للاولة أن تتبناها خلال

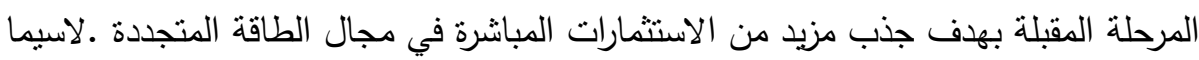

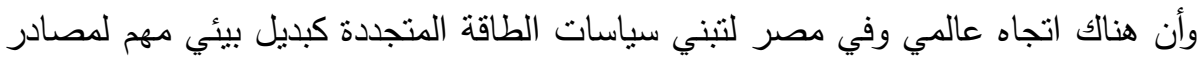
الطاقة الاحفورية .كما أن نتائج البحث تلعب دوراً هاماً لتوضيح الارتباط المهح بين سياسات

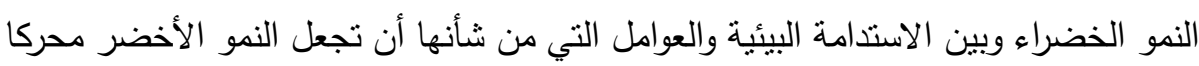
أساسياً لعمليات التتمية المستدامة وليس معوقاً لها. ويضيف البحث للأبعاد العلمية للموضوع من منطلق تركيزه على العلاقة بين تطبيق

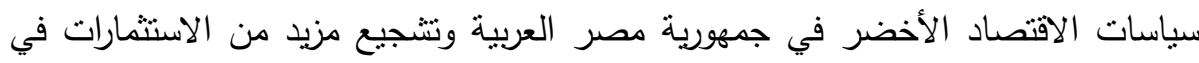

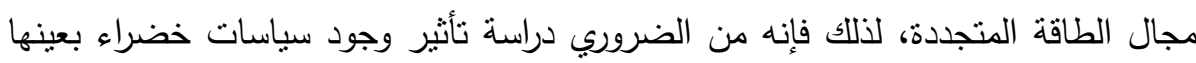

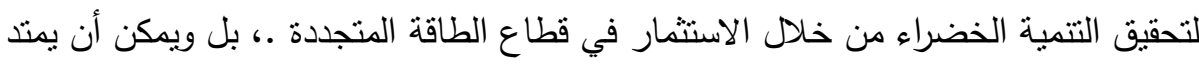
النظر إلى تطبيق سياسات خضراء لجذب استثمارات مباشرة في قطاعات أخرى.

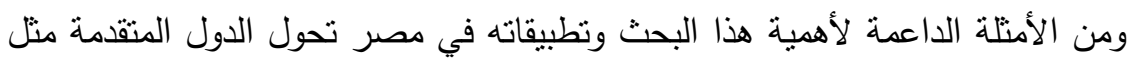

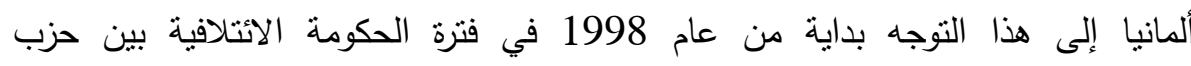
الديمقراطيين الاجنماعيين وبين حزب الخضر حيث بدأت برنامج طموح لتنبي سياسات تهدف الي التحديث والتطوير البيئي Environmental Modernization والتي تضمنت منح تفضيلات جمركية وفرص أفضل للحصول على الكهرباء المستخرجة من مصادر متجددة . حيث كان الهدف المعلن آنذاك هو أن يكون 35\% من إجمالي الكهرباء من مصادر متجددة من مصدية بحلول عام 2020 وكان ذللك في حد ذاته سببا قويا لظهور مزيد من الابتكارات. 


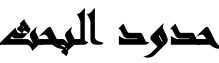

ركز البحث على اثز السياسات الخضراء في تدفق الاستثمارات المباشرة في قطاع الطاقة المتجددة دون التعرض لباقي القطاعات الاقتصادية الهامة لمصر وان كان هناك لأك فرصة لتعميم نتائج هذا البحث على تلك القطاعات، وسوف يقتصر البحث على الحدود

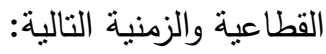

1-الحدود القطاعية: ينتاول البحث الأنواع المختلفة من الاستثمارات في مجالات الطاقة

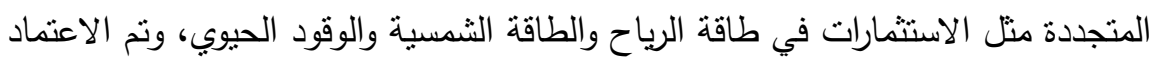
على بيانات وزارة الاستثمار، جهاز شئون البيئة، وهيئة الطاقة المتجددة فيما يتعلق بحجم وتطور الاستتمارات الأجنبية المباشرة في هذا القطاع الحيوي، فضلاً عن البيانات الخاصة وهنة بالثركات العاملة في مصر من واقع البيانات المتاحة أو من واقع ما يبوفر من معلومات

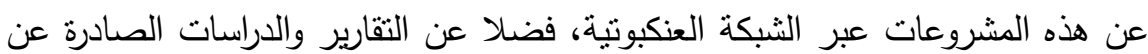
المؤسسات والهيئات والمنظمات الدولية ذات الصلة. r-الحدود الزمنية: يركز البحث على الحدود الزمنية التي تبدأ عام 2001 والمنتهية بحلول

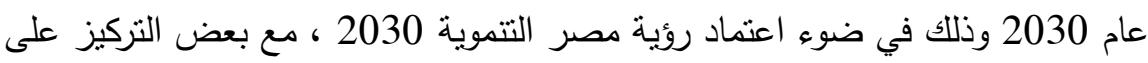

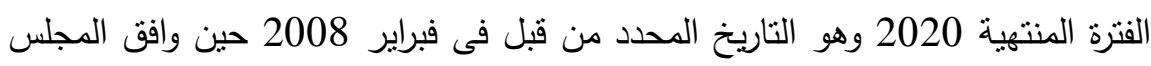

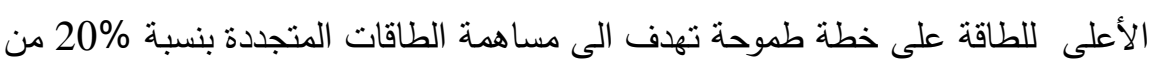

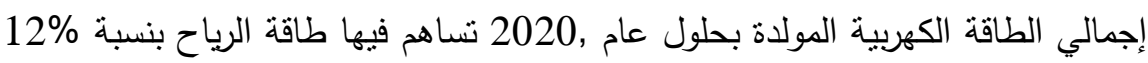

NREA,2014.

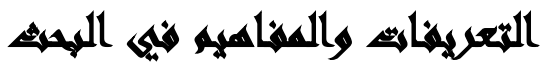

يتعرض البحث لعدة تعريفات ومفاهيم ويأني على رأسها تعريف الاقتصاد الأخضر وذلك للتعرف على ماهيته وما يتضدنه من سياسات وإجراءات وكذا تعريف الاستثمار المباشر ومشتملاته وذلك على النحو التالي: ماهئه وماتصنيه 


\section{1 - تعريف ومفهوم الاقتصاد الأخضر:}

خ يعرف برنامج الأمم المتحدة للبيئة UNEP,2010 الإقتصاد الأخضر على أنه" الإقتصاد

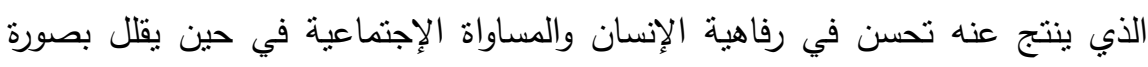

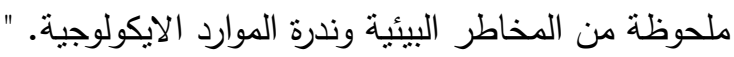

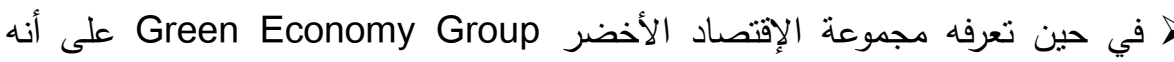
"إقتصاداً مستداماً يكون خال تماماً من إنبعاثات الكربون والذي يتم الحصول فيه على الإنى الطاقة من مصادر متجددة ومن خلال إستخدام تقنيات حديثة للحفاظ على نظافة البيئة"

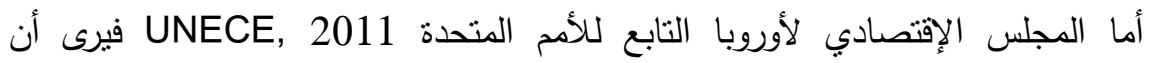
الإقتصاد الأخضر هو " الإقتصاد الذي ينتج عنه رفاهية الإنسان والمساواة الإجتماعية لإنية والذي يتحقق معه انخفاض جوهري في مقدار المخاطر البيئية والندرة الايكولوجية، ويمكن اعتبارة وسيلة لنوفير حياة أفضل لكل الكائنات الموجودة على سطح الأرض، بل بل أيضاً وسيلة لربط الاعتبارات والابعاد الإقتصادية والبيئية والإجتماعية بهدف تحقيق النتمية لهودية المستدامة طويلة الأمد من خلال الأستثمارات صديقة البيئة." وبناء على المفاهيم السابقة يمكن النظر للاقتصاد الأخضر على أنه اقتصاد تقل فيه إنبعاثات الكربون وتزداد بموجبه كفاءة استخدام وتخصيص الموارد الطبيعية، كما يستوعب بهن جميع الفئات الاجتماعية، وفي الإقتصاد الأخضر يكون النمو في الدخل وفرص العمل مدفوعاً بالاستثمارات العامة والخاصة التي تقلل إنبعاثات الكربون والتلوث، وتزيد من كفاءة استهالك الإك الموارد والطاقة، وتمنع خسارة خدمات التتوع البيولوجي، وتحتاج هذه الاستثمارات إلى تحفيز ودعم الحكومات عن طريق الانفاق العام الموجه، وإصلاح السياسات وتغيير اللوائح، بل ويحافظ على مسار التتمية على رأس المال الطبيعي ويحسنة ويعيد بنائه عند الحاجة باعنباره

مصدراً للمنفعة العامة، وبخاصة للفقراء الذين يعتمد أمنهم ونمط حياتهم على الطبيعة. ץ-مفهوم الاستثمار المباشر والإجراءات المصرية في هذا الإطار : حاول العديد من الباحثين

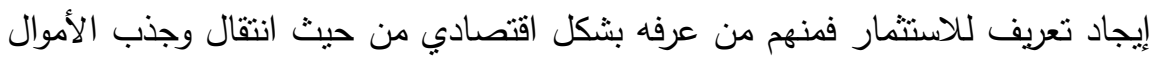

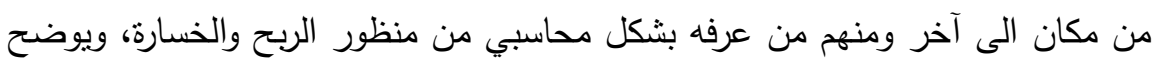


البحث بعضاً من هذه التعريفات لتوضيح المفهوم بقدر الإمكان، مع عرض لأهم إجراءات

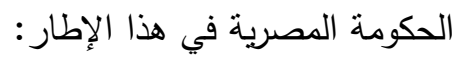

[ برى رضا، 1994 الأستثمار على أنه" قيام شخص طبيعي أومعنوي بمزاولة نشاط

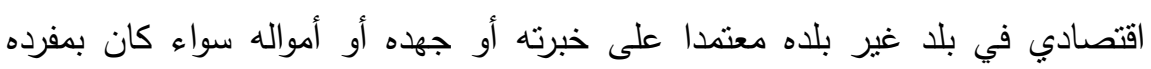

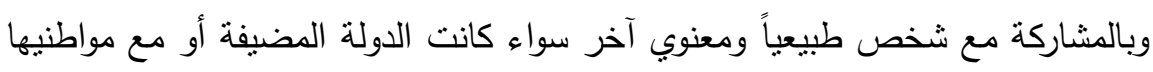
بهدف إنشاء مشروع ومشروعات مشتركة .ويتميز الأستثمار المباشر بطابع مزدوج الأول هو وجود نثاط إقتصادي يمارسه المستثر الأجنبي في بلد المضيف والثاني ملكيته الكلية

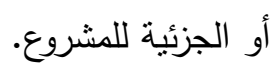

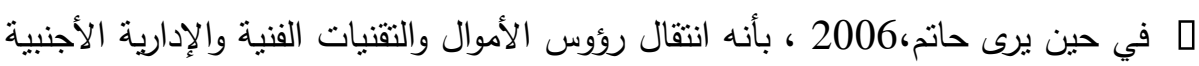

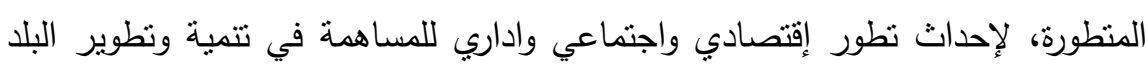
المضيف عن طريق الشركات الوليدة بمشاركة أو بدون مشاركة رأس المال الوطني.

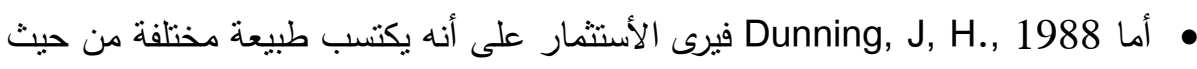

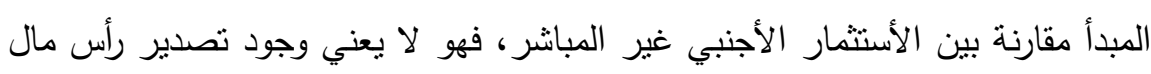

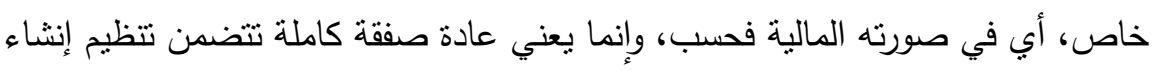

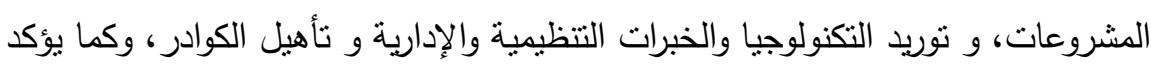
Dunning

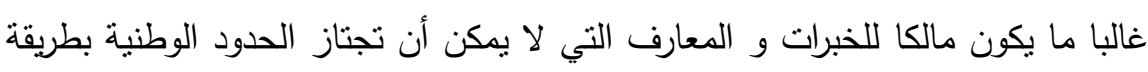
أخرى. وبناء على ما سبق بمكن القول بأن الأستثمار بأنه كل سلعة منقولة أو عقار ، أو خدمة

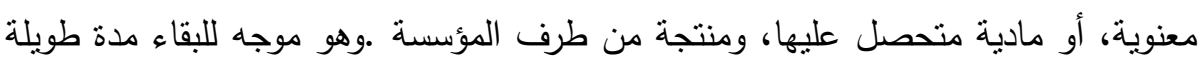

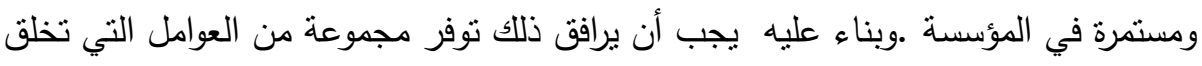

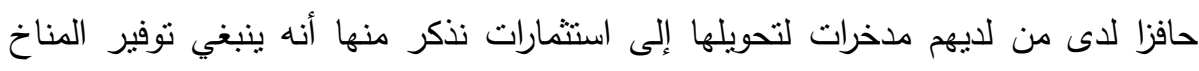

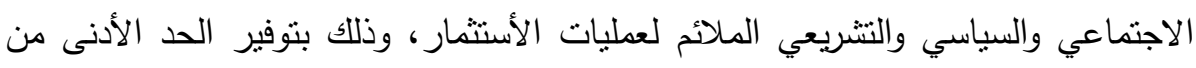

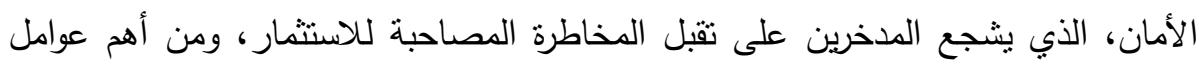

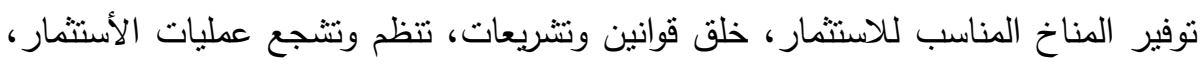

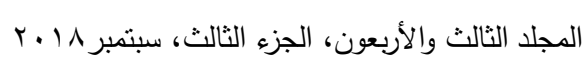


وتحفز وتحمي حقوق المستثمرين، سواء كانوا محليين أو أجانب، وتتظم المعاملات في

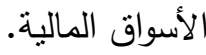

r-مفهوم الاستثمار الأخضر: يرى Investopedia الاستثمار الأخضر بأنه" الأنشطة

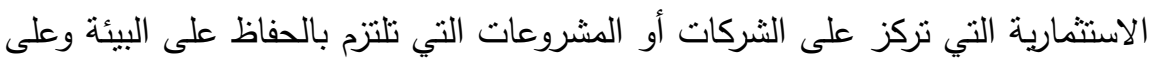
الموارد الطبيعية، والاعتماد على وسائل طاقة جديدة ومتجددة في عمليات الإتتاج، وتتفيذ مشروعات في مجال المياه ومجالات البيئة ذات الصلة بأعمالها، كما أن الاستثمار الأخضر هو الاستثمار الذي يحقق كافة أو معظم إيراداته وإرباحه من خلاهل

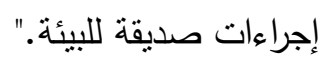

الإجراءات التي اتخذتها الحكومة المصرية لتشجيع الاستثمار في مجال الطاقة المتجددة:

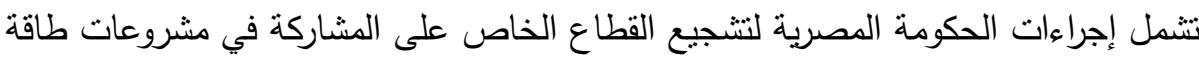

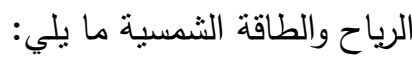
> الحصول على موافقة جميع الجهات صاحبة الولاية على الارض وتطهيرها من الألغام.

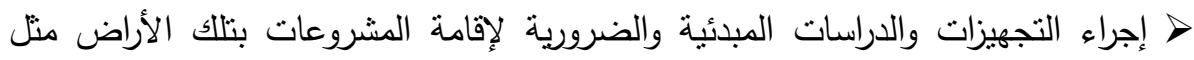
الدراسات البيئية ودراسات هجرة الطيور ، ودراسات أبحاث التربة وغيرها.

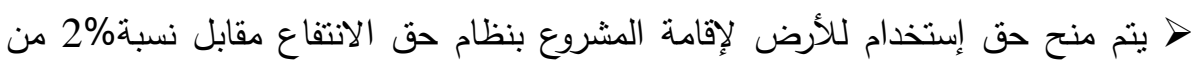

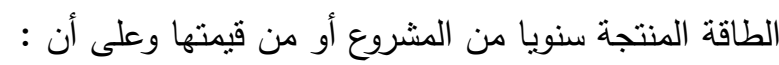

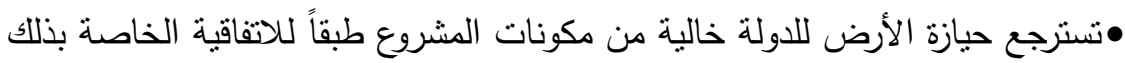

$$
\text { بنهاية العمر الإنتاجى للمشروع • العند }
$$

•تسترد الهيئة من المستثر قيمة التكاليف الفعلية التى تكلفتها فى إعداد وتجهيز الأرض وتدخل هذه التكاليف ضمن التكلفة الأستثمارية للمشروع. إبرام اتفاقيات لشراء الطاقة المنتجة من محطات الرياح لمدة تتراوح بين 25 - 20 سنة بسعر يغطى التكلفة والعائد من الاستثمار . > نوفير ضمان من الحكومة للالتزامات المالية للشركة المصرية لنقل الكهرباء طبقا لبنود

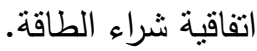


> تحديد عملة الشراء على أن يتضمن سعر شراء الطاقة نسبة بالعملة المحلية لتغطية التكاليف المحلية والإنتاج المحلى والباقى بالعملة الأجنبية.

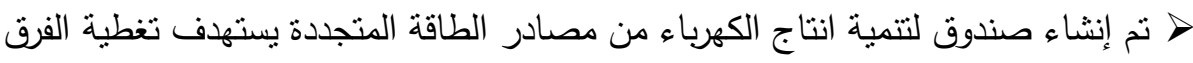
بين سعري الانتاج والبيع وكذلك تقديم الضمانات المطلوبة ومواجهة التغير في أسعار الصرف.

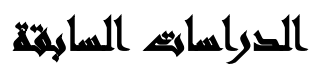

اتفقت الأدبيات على أن القرار الاستثماري للشركات متعددة الجنسيات يعتمد على عدة عوامل تتعلق بسياسات الدولة المضيفة وعلى رأسها السياسات المتعلقة بالبيئات الاقتصادية والسياسية والتشريعية والقضائية التي تطبقها الدولة الحاج،1998 ، وقد أوضح 2010وجود علاقة عكسية بين الاستدامة البيئية وبين التوجه نحو زيادة Chakroborty, كل من التجارة الدولية في السلع والاستثمارات المباشرة الوافدة للدولة، وأن الاستدامة البيئية تتأثر ايجابياً بالصادرات الخدمية وبالتدفقات الاستثمارية الخارجة من الدولة .في حين أشنار

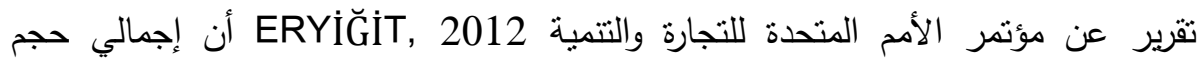
الاستثمارات الأجنبية المباشرة ارتفع من 7450 مليار دولار عام 2000 إلى نحو 20438

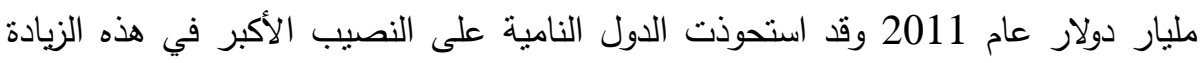
بنسبة بلغت44.9\% ، كما خلص التقرير إلى أن الدول النامية كانت تلجأ لسياسات وممارسات مدمرة للبيئة كتلك التي اعتمدت على الطاقة الاحفورية بشكل يهدد البيئة.

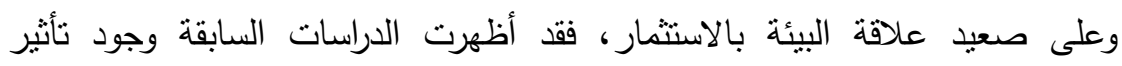
للاستثمارات المباشرة على البيئة والتتمية البيئية فالتدفقات الاستثمارية الوافدة من دول منظمة البئهة

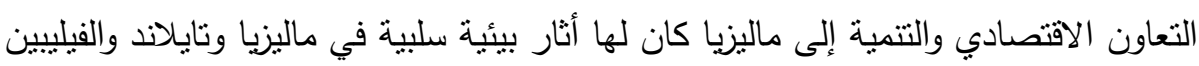

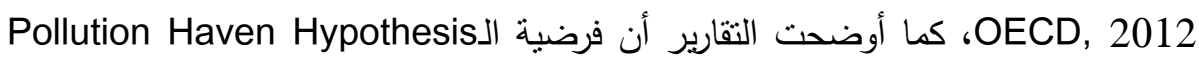
(التتمية القائمة على استنزاف الموارد وتجاهل اعتبارات البيئة) كان لها تأثنر واضح في حجم التهات ومدى تدفق الاستمارات المباشرة من الدول المنقدمة للدول النامية خاصة في الصناعات الملوثة للبيئة Chakraborty, 2012 وقد تم ملاحظة هذه الظاهرة في عدد كبير من الدول

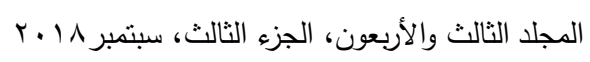


النامية، وقد نرتب على ظهور الصين والنمور الأسيوية كدول منلقية للاستثمارات أن أولى مجموعة من الباحثين الاهتمام بتقييم العلاقة بين الاستثمارات والبيئة.

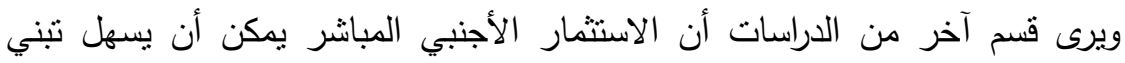

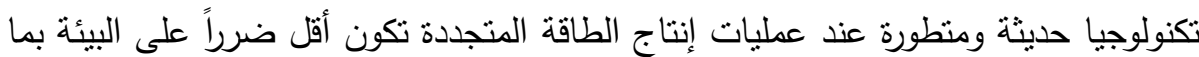
يؤدي إلى كفاءة أكبر في استخدام الوقود، وانتقال أفضل للتكنولوجيا Acharyya, 2009 وقد تجلت أدلة وجود استثمارات خضراء في غياب فرضية PHH في كثير من الدول النامية وعلى

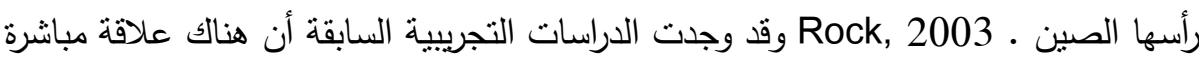

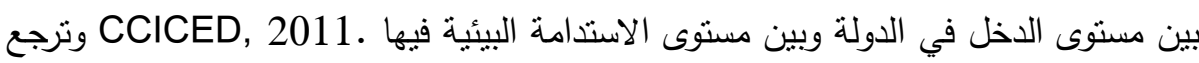

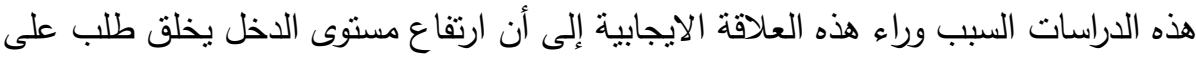
بيئة أنظف، كما وجدت الدراسات أيضا أن هناك علاقة بين البيئة وبين التنمية البشرية

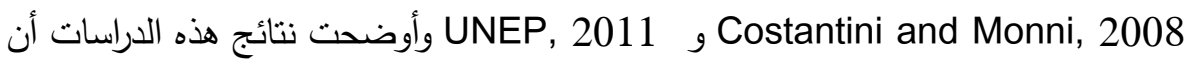
التتمية البشرية تؤدي إلى مزيد من التحرك نحو التتمية البيئية.

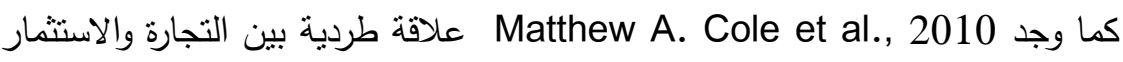
من ناحية وبين البيئة من ناحية اخرى من منظور التأثير المباشر الذي يحدثانه على الموارد

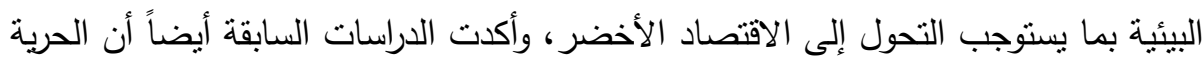

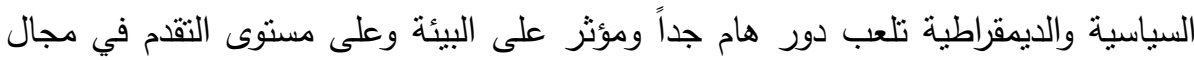
البيئة في الدولة Fredriksson et al., 2003 ، فوجود قدر مناسب من الديمقراطية من شأنه وجود حوكمة أرشد ومن ثم وجود سلع بيئية، فالحرية الديمقراطية والحريات الاجتماعية

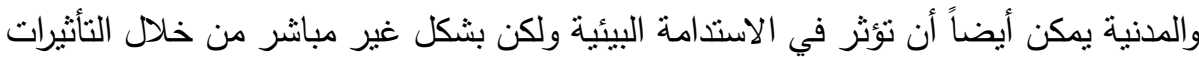
الإيجابية على الدخل، بل والأكثر من ذلك على ممارسة الحقوق السياسية والحريات المدنية، كما أنها تيسر وتزيد من قدر الثفافية التي تمكن المواطنون والمجموعات المدنية من زيادة الوعي البيئي لما تتيحه من مجال رحب للنشطاء في مجال البيئة للتعبير عن أهدافهم

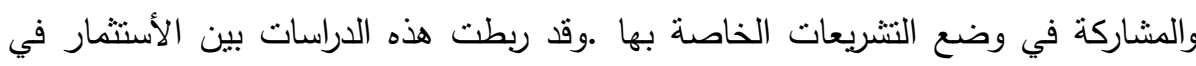
الطاقة المتجددة وبين التتمية المستدامة. 
ولعل المعنى الأساسي لمفهوم الاقتصاد الاخضر هو أنه حزمة السياسات الاقتصادية

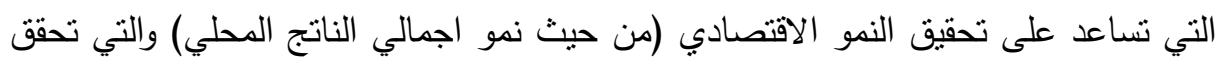

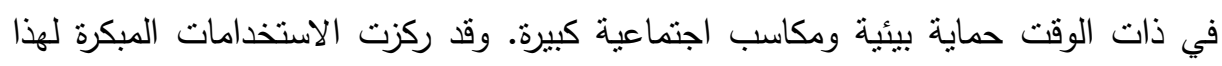

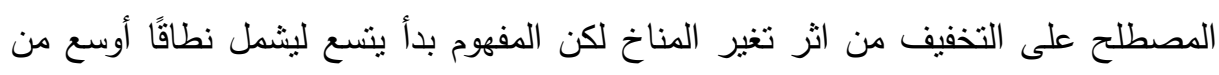

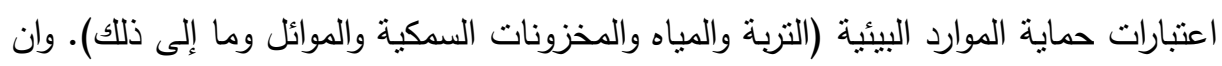

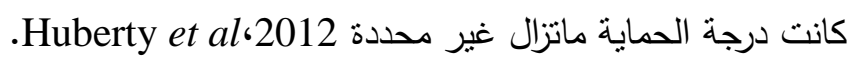

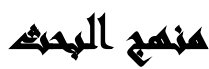

أكدت التطورات الدولية الأخيرة في مجال التخطيط الاقتصادي أهمية التعرض للأبعاد

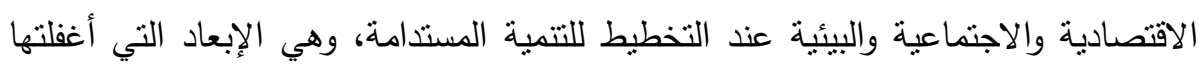

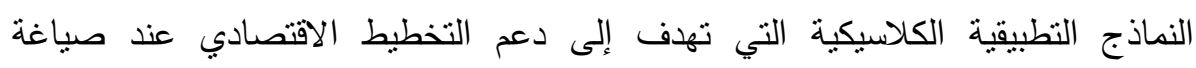

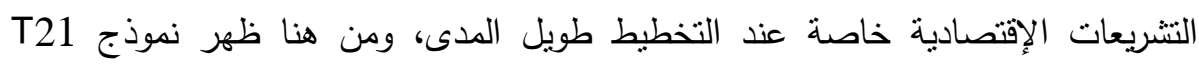

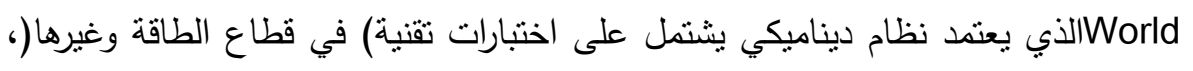

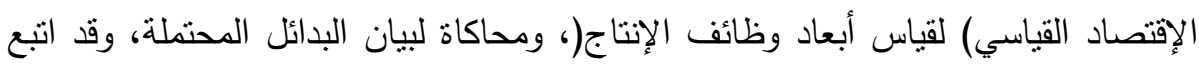
تقرير الإقتصاد الأخضر الصادر عن برنامج الأمم المتحدة البيئي

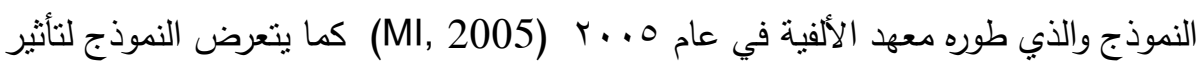
سياسات الإقتصاد الأخضر Green (G) على معدلات نمو الأستثمار في مقابل معدلات

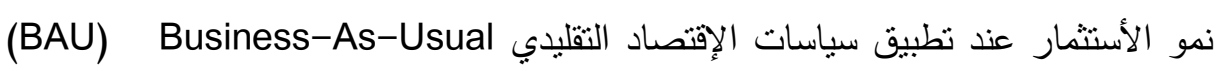

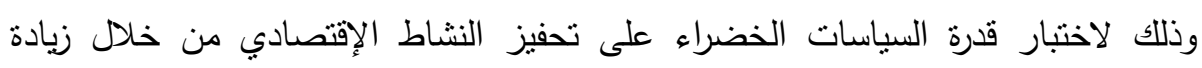

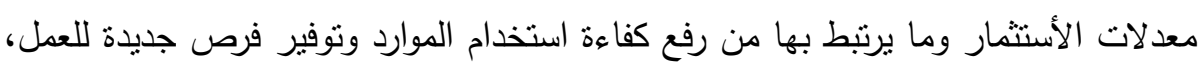
ويتبع النموذج السيناريوهات التالية للوصل للنتائج:

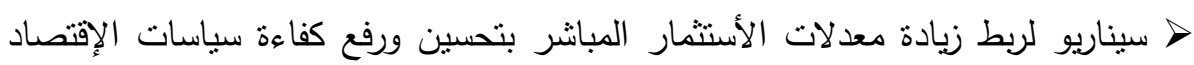
الأخضر التي بتضمنها البحث وهما السيناريوهان المشار اليها بـ. G-Scenario > سيناريو زيادة معدلات الأستثمار في ظل نطبيق سياسات الإقتصاد التقليدي ويشار اليه في البحث Scenario -BAU 
> مقارنة السيناريو الأول بالسيناريو الثاني للوصول إلى النتائج ومن ثم التوصيات.

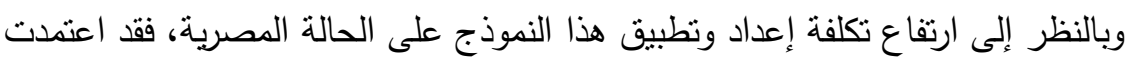
البحث على أسلوب الاستقصاء) ملحق رقم (1 لتقييم المتغيرات المختلفة التي يشملها نموذج T21 World

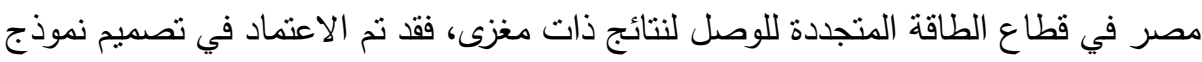

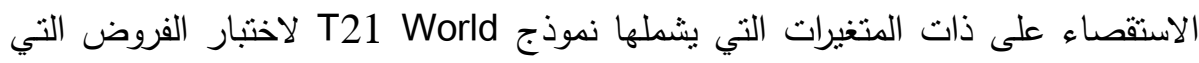

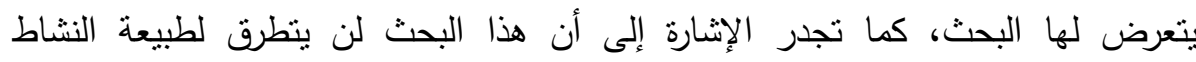

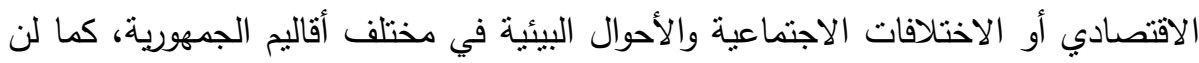

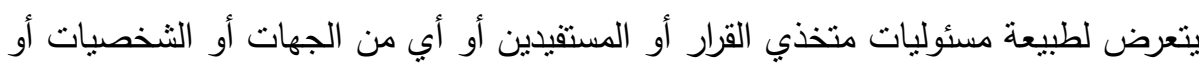
المؤسسات خاصة الحكوميين، وفيما يلي نعرض المنهج المتبع: 1-مجتمع البحث: يشمل المجتمع البحث كل من الثركات المستثمرة في القطاع الطاقة

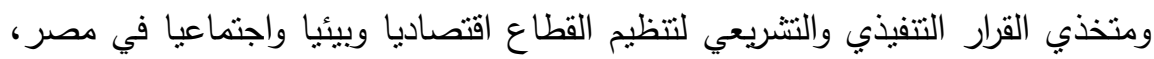

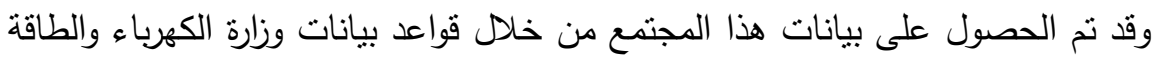

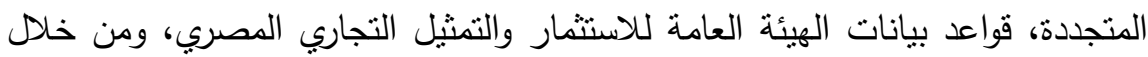
الاتصالات والمقابلات الفردية التي أجراها الباحث مع مسئولي وزارة الاستثمار ، وقد أمكن وندئن تقدير عدد مفردات هذا المجتمع بنحو 273 مفردة. r-اختيار عينة البحث: اعتمد البحث على سحب عينة طبقية عشوائية لكل مجتمع من مجتمعي الدراسة في ضوء مجموعة من الافتراضات الإحصائية والمتمثلة في درجة الثقة

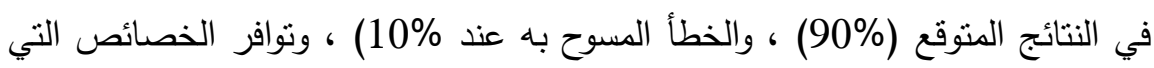

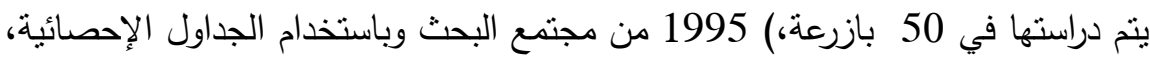

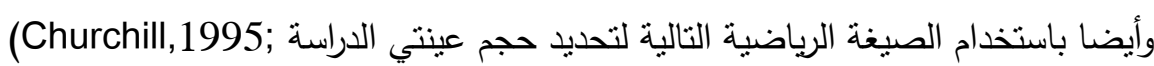
Aaker, Kumar, Day, 1998) :

$$
\text { حيث: ن = حجم العينة. }
$$
ق = القيمة المعيارية المقابلة لدرجة الثقة في نتائج الدراسة. 
ح = الانحراف المعباري في مجتمع الدراسة.

خ = الخطأ المسموح به في عينة الدراسة.

ونظرا لأن الانحراف المعياري لمجتمع الدراسة غير معلوم، فقد تم الاستعاضة عنه

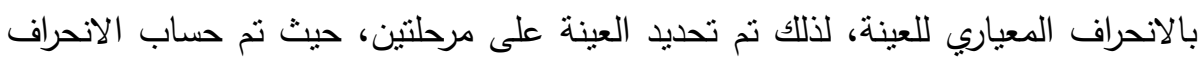

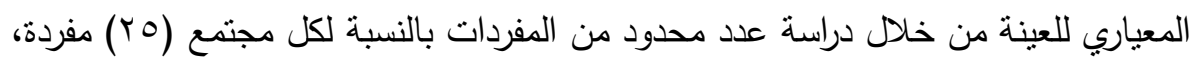
والتي توقع الباحث وجود تباين واضح في الإجابة عليهما، وذللك بالنسبة لأحد الأسئلة

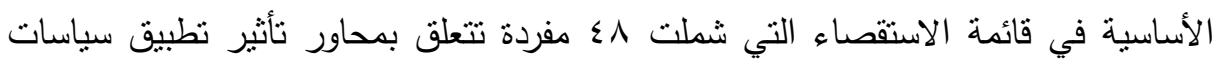

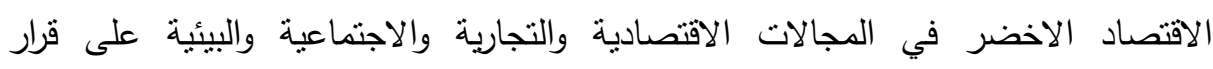

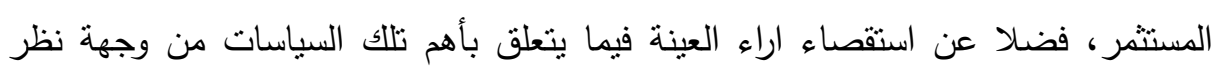
عينة الدراسة، وبناء عليه نم تحديد حجم عينة البحث على النحو التالي:

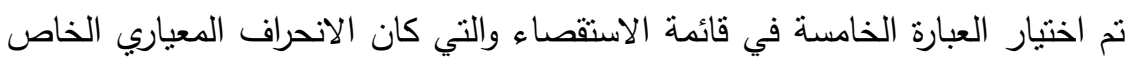

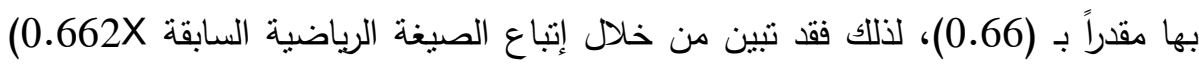

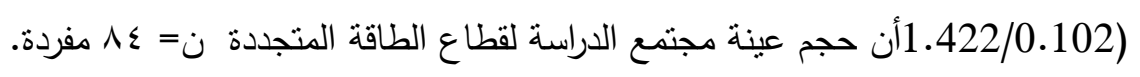

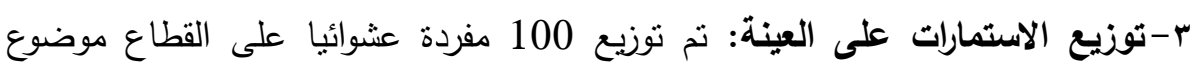

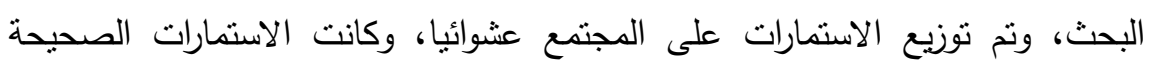

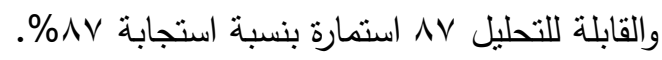
؛ - الأساليب الإحصائية: بعد تفريغ بيانات الاستبيانات الصالحة نم استخدام البرنامج الإحصائي (spss في إجراء التحليل الإحصائي لبيانات البحث الميدانية.

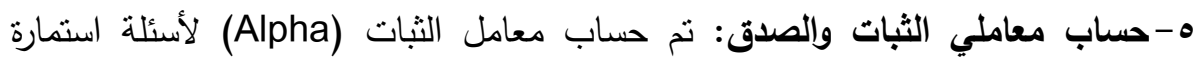
الاستقصاء) ما يسمى بمعامل الاعتمادية(، وذللك لبحث مدى الاعتماد على نتائج البحث

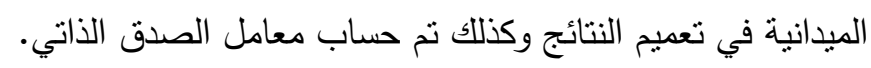
צ-الإحصاء الوصفي: نم استخدام الوسط الحسابي والانحراف المعياري لتوضيح منوسط وتئ وتباين الآراء حول متغيرات البحث، ونم استخدام والتوزيع التكراري لوصف التهفي عينة البحث.

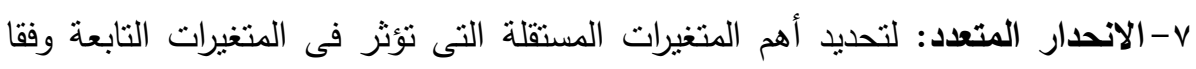
للمنطق الاقتصادي والاجتماعي والبيئي.

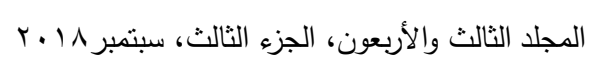




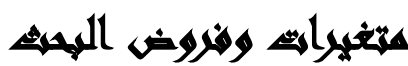

فيما يلي المتغيرات والفروض التي تتاولها البحث وذلك على النحو التالي: 1 - متغيرات البحث: يمكن تقسيمها إلى متغيرات تتعلق بالبدائل المتاحة وتتعلق بسياسات

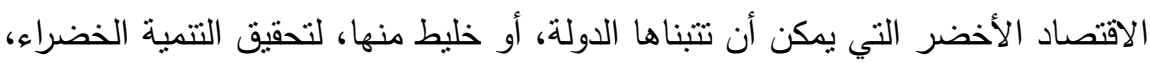
ومن ناحية أخرى المتغيرات أو العوامل المتعلقة بقدرة الدولة على جذب البهاد الاستثمارات الأجنبية المباشرة في مجال الطاقة المتجددة، وفيما يلي يتم إلقاء الضوء على هذه هذه المتغيرات، ويوضح الجدول رقم (1) المتغيرات الأساسية للمقارنة بين S-Scenario و Scenario -BAU التي ينم دراستها للحصول على النتائج والتوصيات المتعلقة

$$
\text { بموضوع البحث. }
$$

r- فروض البحث: يعتمد البحث على مجموعة الفرض الأساسي والفروض الفرعية التالية

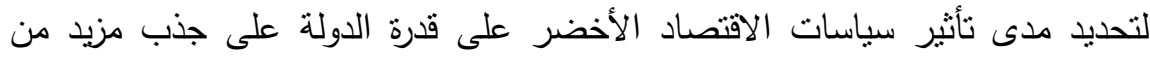
الاستثمارات الأجنبية المباشرة في مجال الطاقة المتجددة وذللك على النحو التالي:

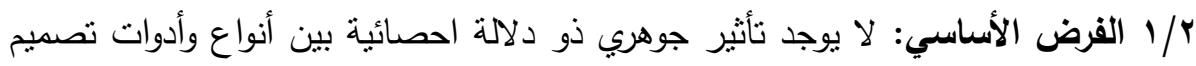

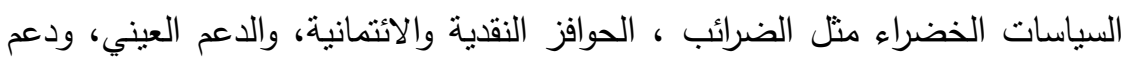
البحوث والتطوير والابتكار على القرارات الأستثمارية لرجال الأعمال".

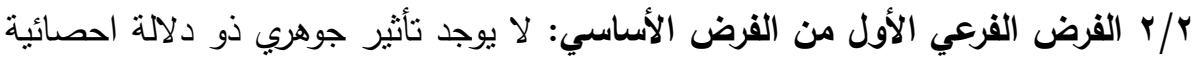
بين السياسات فى المجال الإقتصادى والتجارى على القرارات الأستثارية لرجال

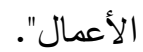

r/ الفرض الفرعي الثانى من الفرض الاساسي: لا يوجد تأثثر جوهري ذو دلالة احصائية

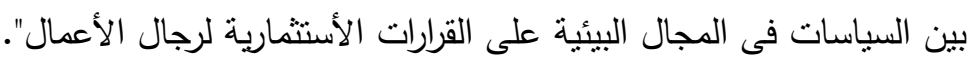

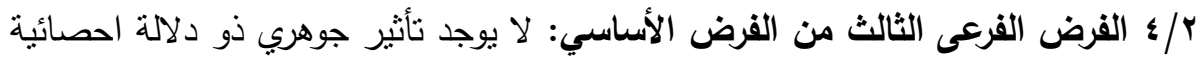
بين السياسات فى المجال الاجتماعى على القرارات الأستثمارية لرجال الأعمال". 
جدول رقم( (1): المتغيرات الأساسية التي تحكم كل سيناريو

\begin{tabular}{|c|c|}
\hline تدفق الاستثمارات في ظل سيناريو تبني سياسات الأخضر & 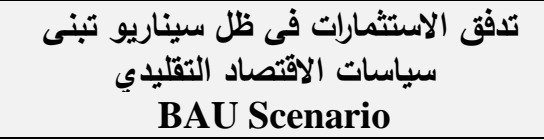 \\
\hline ضرائب وتعريفات تفضيلية & الضرائب على الطاقة التقليدية \\
\hline ضرائب اهلاك تفضيلية & ضرائب إهلاك تقليدية \\
\hline سياسات دعم مرتبط بانتاج الطاقة الجديدة & دعم الطاقة التقليدي \\
\hline سياسات تتظيم تفضيلية & سياسات التتظيم الحالية \\
\hline تشريعات بيئية مرتبطة بالانتاج الأخضر & التثريعات البيئية الحالية \\
\hline غرامات مخالفة الاشتراطات البيئة مشددة & غرامات مخالفة الاشتراطات البيئية الحالية \\
\hline سياسات تخصيص أراضى تفضيلية & سياسات تخصيص الأراضى الحالية \\
\hline ربحية الثركات حال تننى سياسات خضراء & ربحية الثركات في ظل السياسات التقليدية \\
\hline آليات متثّددة لإنفاذ القوانين الييئية & آليات إنفاذ القوانين البيئية الحالية \\
\hline أثر السياسات الخضراء على معدلات التوظف & اثر السياسات الحالية على معدلات التوظف \\
\hline
\end{tabular}

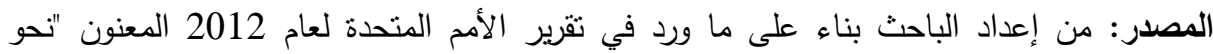

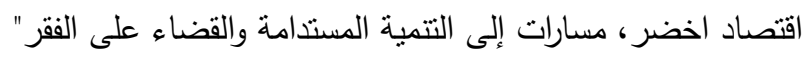

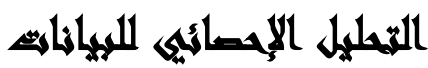

بعد ترميز وتفريغ البيانات التي تم الحصول عليها بعد تطبيق الاستبيان، تم استخدام الإصدار الثاني والعشرون من البرنامج الاحصائى (SPSS)The Statistical Package for Social Sciences التالي: أولاً ثبات وصدق الاستقصاء.

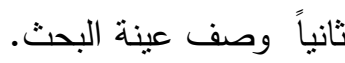
ثالثاً: اختبارات الفروض وتحليل النتائج ويتتاول الباحث كل عنصر من العناصر السابقة بشيء من التفصيل كما يلى:

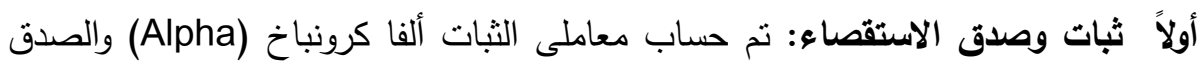

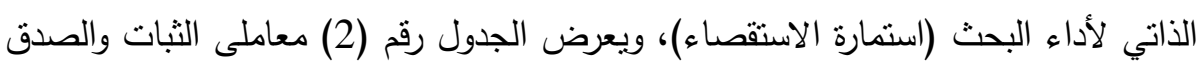

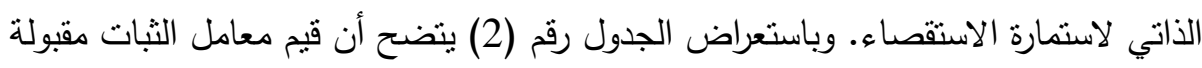

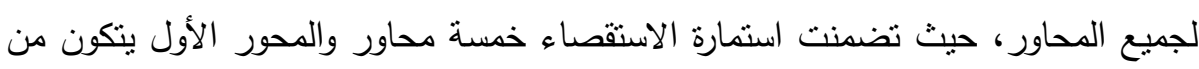

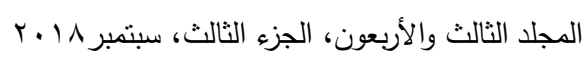


ثلاثة ابعاد وكل بعد يتكون من مجموعة من العبارات تأخذ شكل ليكرت الخماسى، وتراوحت

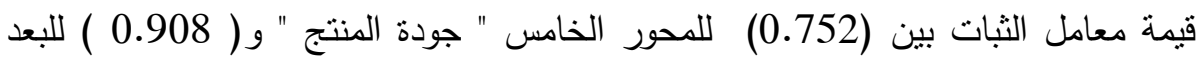
الأول من المحور الأول " في المجال الإقتصادي والتجاري"، وتراوحت قيمة معامل الصدق

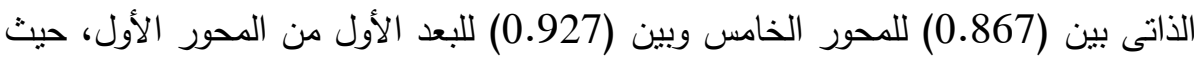

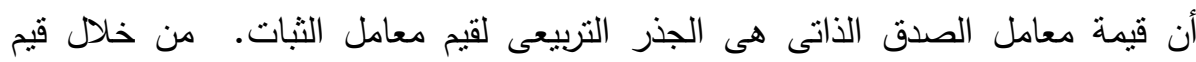

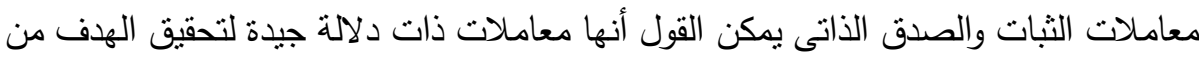
البحث ويمكن الاعتماد عليها فى تعميم المخرجات على المجتمع ككل. ثانياً: وصف عينة البحث: يعرض جدول رقم (3) توزيع عينة البحث حسب المبث المتغيرات التنظيمية والديموجرافية، ويتضح من الجدول ان نسبة $66.7 \%$ من اجمالى العينة ذكور ، ونسبة 39.3\% من اجمالى العينة يقعون فى الفئة العمرية من 30 لأقل من 35 سنة، ونسبة 35.7\%من اجمالى العينة حاصلين على مؤهل جامعى، ونسبة 64.3\% من من اجمالى العينة يعملون بوظيفة فنية، ونسبة 35.7\% من إجمالى العينة لهم سنوات خبرة من 5 لأقل من 10

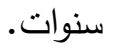
جدول رقم(Y): معاملى الثبات لألفا كرونبا والصدق الذاتى لاستمارة الاستقصاء

\begin{tabular}{|c|c|c|c|}
\hline معامل الصدق & $\begin{array}{c}\text { معامل) } \\
\text { (Alpha) } \\
\text { (الثات }\end{array}$ & 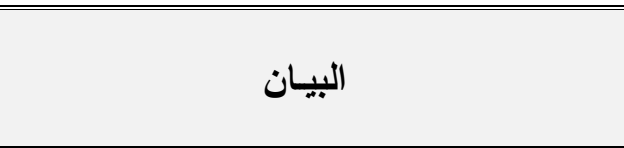 & 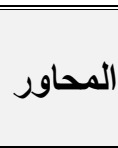 \\
\hline & & السياسات الخضراء في قطاع الطاقة المتجددة & الأول \\
\hline 0.953 & 0.908 & في المجال الإقتصادي والتجاري & أولاً \\
\hline 0.927 & 0.860 & في المجال البيئي ـ ـ & ثنانيا \\
\hline 0.905 & 0.819 & في المجال الاجتماعي & ثالثا \\
\hline 0.910 & 0.829 & في قطائل وآليات قرارات الأستثمار الأجنبي المباشر & الثنانى \\
\hline 0.934 & 0.873 & تنبنى الدول لسياسات الانتاج الاخضر & 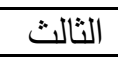 \\
\hline 0.915 & 0.838 & التكلفة النهائية للمنتج & 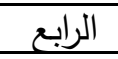 \\
\hline 0.867 & 0.752 & جودة المنتج & 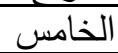 \\
\hline
\end{tabular}

المصدر: من إعداد الباحث من واقع مخرجات برنامج SPSS 
جدول رقم(r): توزيع عينة البحث (n = (n)

\begin{tabular}{|c|c|c|c|}
\hline \multicolumn{2}{|c|}{ النسيةة\% } & التكرار & البيان \\
\hline 66.7 & 56 & ذكر & \\
\hline 33.3 & 28 & انثى & اللوع \\
\hline 21.4 & 18 & أقلَ من 30 سنة & \\
\hline 39.3 & 33 & من 30 لأقل من 35 سنة & \\
\hline 27.4 & 23 & من 35 لأقل من 40 سنة & السن \\
\hline 11.9 & 10 & 404سنة فأكثر & \\
\hline 19.0 & 16 & مؤهل متوسط & \\
\hline 31.0 & 26 & مؤهل فوق منوسط & \\
\hline 35.7 & 30 & مؤهل عالى & الموهل العلمى \\
\hline 14.3 & 12 & دراسات عليا & \\
\hline 64.3 & 54 & فنى & \\
\hline 35.7 & 30 & إدارى & مجال العمل \\
\hline 20.2 & 17 & أقل من 5 سنوات & \\
\hline 35.7 & 30 & من 5 لأقُلِ من 10 سنوات & \\
\hline 28.6 & 24 & من 10 لأقلَ من 15 سنة & سنوات الخبرة \\
\hline 15.5 & 13 & 15سنة فأكثر & \\
\hline
\end{tabular}

المصدر: من إعداد الباحث من واقع مخرجات استمارات الاستيان وباستخدام برنامج SPSS.

\section{اختبارات الفروض وتحليل النتائج:}

أولاً: الفرض الاساسي: "لا يوجد نأثثر جوهري ذو دلالة احصائية بين أنواع وأدوات تصميم

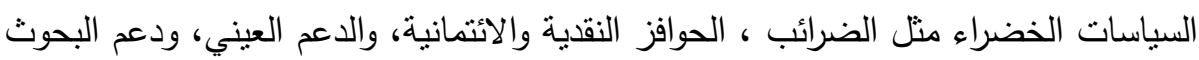

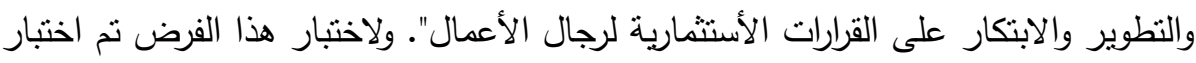

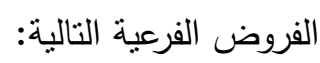

1- الفرض الفرعى الأول من الفرض الاساسي: "لا يوجد تأثير جوهري ذو دلالة احصائية

بين السياسات فى المجال الإقتصادى والتجارى على القرارات الأستثمارية لرجال الأعمال".

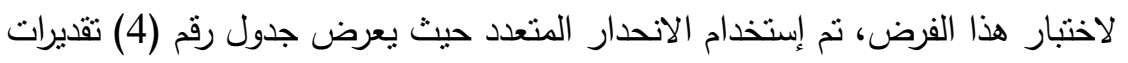

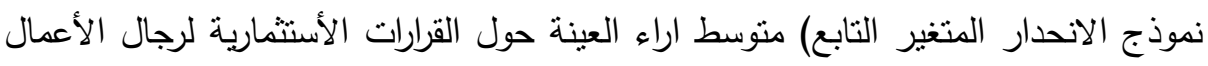

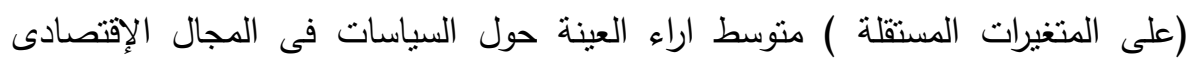

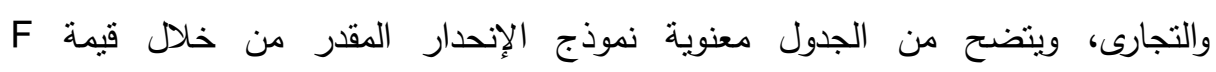


(185.658)، وقيمة(sig=0.000) ، وتفسر 87.4\% من التغيرات التى تحدث فى المتغير

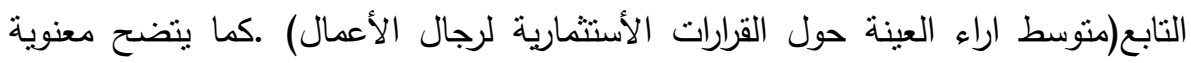

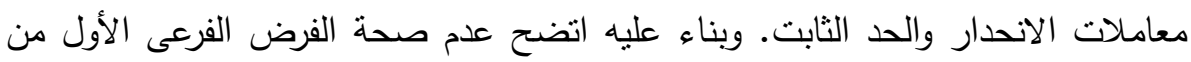
الفرض الأول وصحة الفرض البديل: "يوجد تأثير جوهري ذو دلالة احصائية بين السياسات فى المجال الإقتصادى والتجارى على القرارات الأستثمارية لرجال الأعمال". r- الفرض الفرعى الثانى من الفرض الاساسي: " لا يوجد تأثير جوهري ذو دلالة الألة احصائية بين السياسات فى المجال البيئيى على القرارات الأستثمارية لرجال الأعمال". جدول رقم (؛): تقديرات نموذج الاتحدار المتغير التابع (متوسط اراء العينة حول القرارات الأستتمارية لرجال الأعمال (على المتغيرات المستقلة ) منوسط اراء العينة العينة

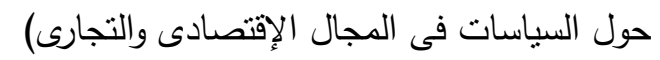

\begin{tabular}{|c|c|c|c|c|c|}
\hline \multicolumn{4}{|c|}{ التقديرات } & \multirow{2}{*}{$\begin{array}{c}F \\
\text { (sig.) }\end{array}$} & \multirow{2}{*}{ معامل التحديد R $^{2}$} \\
\hline Sig. & $t$ & ( & & & \\
\hline .013 & 2.544 & .568 & الحد الثابت & \multirow{4}{*}{$\begin{array}{c}185.658 \\
(0.000)\end{array}$} & \multirow{4}{*}{0.874} \\
\hline .013 & 2.547 & .181 & $\times 1.24$ & & \\
\hline .000 & 6.669 & .375 & $\mathrm{x} 1.33$ & & \\
\hline .004 & 2.928 & .255 & $\mathrm{x} 1.3$ & & \\
\hline
\end{tabular}

المصدر: من إعداد الباحث من واقع مخرجات برنامج SPSS.

لاختبار الفرض الفرعي الثاني من الفرض الاساسي، نم إستخدام الانحدار المتعدد حيث

يعرض جدول رقم (5) تقديرات نموذج الانحدار المتغير التابع) متوسط اراء العينة حول

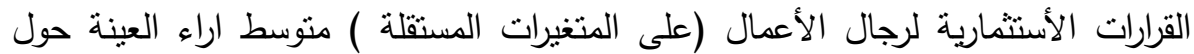
السياسات فى المجال البيئيى(، ويتضح من الجدول معنوية نموذج الإنحدار المقدر من خلال قيمة F (196.804)، وقيمة (sig=0.000) ، كما يتضح معنوية معاملات الانحدار والحد الثابت وتقسر 88.1\% من التغيرات التى تحدث فى المتغير التابع( متوسط اراء العينة حول

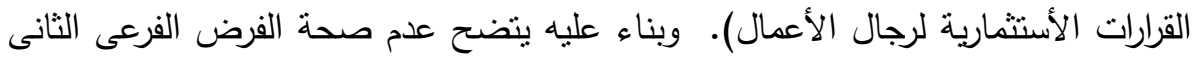
من الفرض الأول وصحة الفرض البديل: "يوجد تأثثير جوهري ذو دلالة احصائية بين السياسات فى المجال البيئيى على القرارات الأستثمارية لرجال الأعمال". 
r- الفرض الفرعى الثالث من الفرض الاساسي: “لا بوجد نأثير جوهري ذو دلالة احصائية بين السياسات فى المجال الاجتماعى على القرارات الأستثمارية لرجال الأعمال".

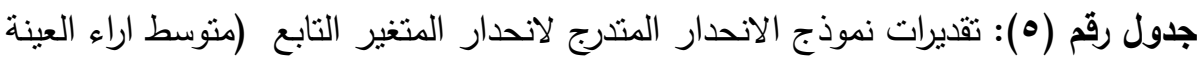

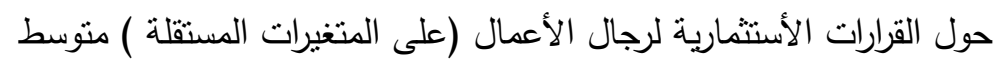

اراء العينة حول السياسات فى المجال البيئيى)

\begin{tabular}{|c|c|c|c|c|c|}
\hline \multicolumn{4}{|c|}{ التقديرات } & \multirow{2}{*}{$\begin{array}{c}F \\
\text { (sig.) }\end{array}$} & \multirow{2}{*}{ معامل التحديا } \\
\hline Sig. & $\mathbf{t}$ & 0 & & & \\
\hline .070 & 1.837 & .321 & الحد الثابت & \multirow{4}{*}{$\begin{array}{c}196.804 \\
(0.000)\end{array}$} & \multirow[t]{4}{*}{0.881} \\
\hline .000 & 9.460 & .786 & $x 2.3$ & & \\
\hline .000 & 8.820 & .429 & $x 2.11$ & & \\
\hline .000 & 4.194 & .321 & $\times 2.8$ & & \\
\hline
\end{tabular}

المصدر: من إعداد الباحث من واقع مخرجات برنامجSPSS ل

لاختبار هذا الفرض، تم إستخدام الانحدار المتعدد حيث يعرض جدول من رقدم (6) تقديرات

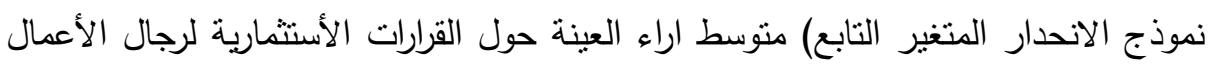
(على المتغيرات المستقلة ) منوسط اراء العينة حول السياسات فى المجال الإجتماعى،

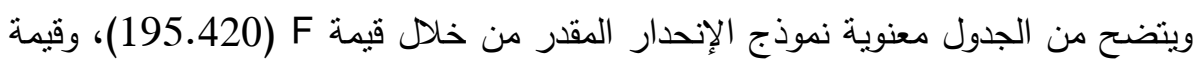

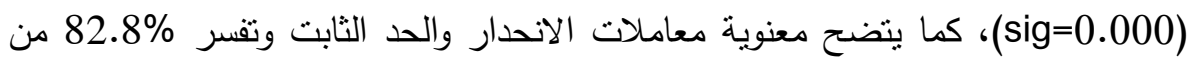
التغيرات التى تحدث فى المتغير التابع، (متوسط اراء العينة حول القرارات الأستثمارية لرجال (الأعمال).

وبناء عليه ينضح عدم صحة الفرض الفرعى الثالث من الفرض الأول وصحة الفرض دأل

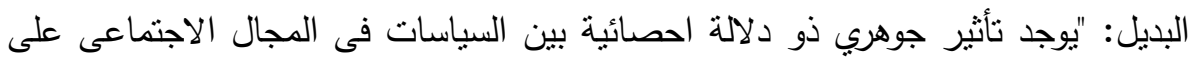
القرارات الأستثمارية لرجال الأعمال". 
جدول رقم (†): نموذج الانحدار المتدرج لانحدار المتغير التابع (متوسط اراء العينة حول

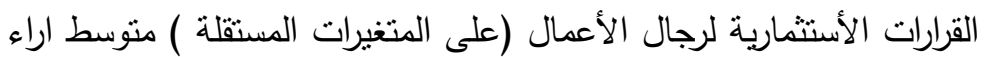

العينة حول السياسات فى المجال الاجتماعي)

\begin{tabular}{|c|c|c|c|c|c|}
\hline \multicolumn{4}{|c|}{ التقديرات } & \multirow{2}{*}{$\begin{array}{c}\mathbf{F} \\
\text { (sig.) }\end{array}$} & \multirow{2}{*}{ 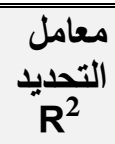 } \\
\hline Sig. & $\mathbf{t}$ & Q & & & \\
\hline .000 & 22.492 & 1.932 & الحد الثابت & \multirow{3}{*}{$\begin{array}{c}195.420 \\
(0.000)\end{array}$} & \multirow[t]{3}{*}{0.828} \\
\hline .000 & 6.500 & .364 & $\times 3.5$ & & \\
\hline .007 & 2.792 & .120 & $\times 3.1$ & & \\
\hline
\end{tabular}

مما سبق يتضح عدم صحة الفرض الاساسي وصحة الفرض البديل: يوجد تأثثر جوهري ذو دلالة احصائية بين أنواع وأدوات تصميم السياسات الخضراء مثل الضرائب ، الحوافز النقدية والائتمانية، والدعم العيني، ودعم البحوث والنطوير والابتكار على القرارات الأستثمارية لرجال

الأعمال".

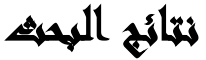

1-أن أهم السياسات فى المجال الإقتصادى والتجارى التى تؤثثر فى المتغير التابع بحسب

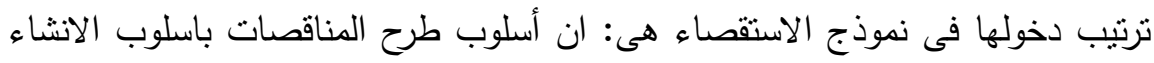

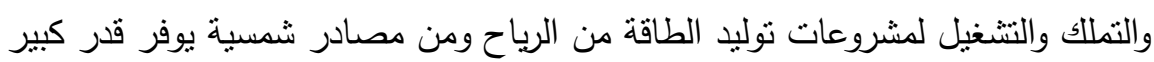

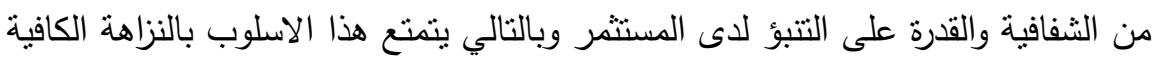
لتطوير القطاع وجذب الأستثمارات اليه.

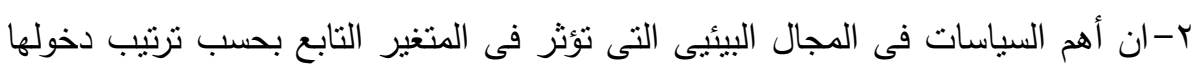

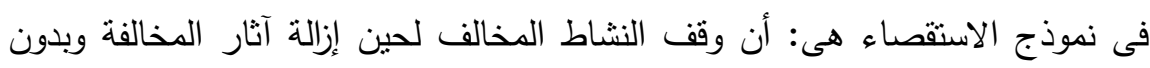
المساس بأجور العاملين فيه جنبا إلى جنب مع غيرها من غرامات أنس أخرى سوف يحد من

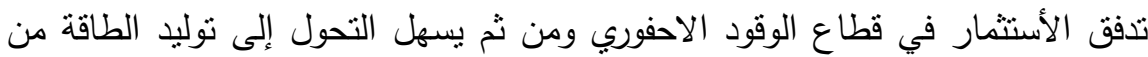

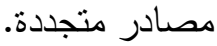


r-ان أهم السياسات فى المجال الإجتماعى التى تؤثر فى المتغير التابع بحسب ترتيب

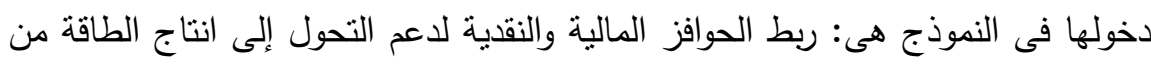
المصادر المتجددة بتوظيف حد أدنى من العمالة.

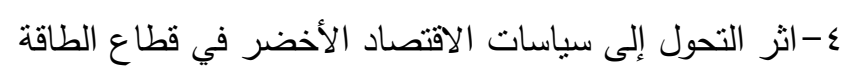

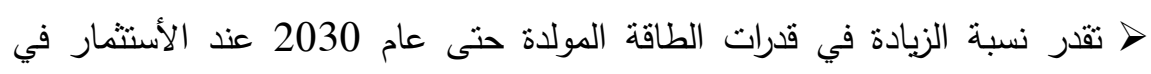

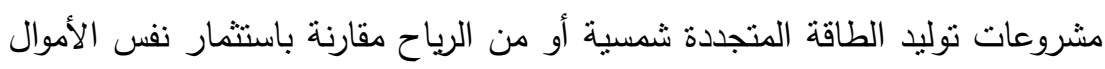
للتوسع في مشروعات حالية بنسبة 15\%-12 مقارنة بالاستمرار في تطبيق السياسات الحالية .

> تقدر نسبة انخفاض الإنبعاثات الحرارية على المدى البعيد حتى عام 2030 بنسبة ل20\%-16 مقارنة بالاستمرار في تطبيق السياسات الحالية.

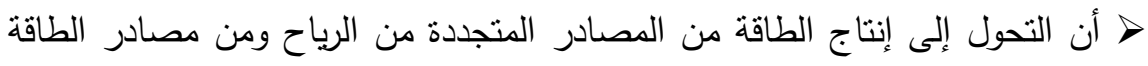
الثمسية من شأنه أن يزيد عدد العمالة على مدار العشر سنوات المقبلة بنسبة نتراوح بين ؟-. 1 \% مقارنة بالاستمرار في تطبيق السياسات الحالية.

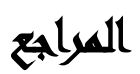

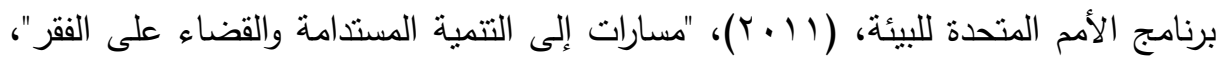
مرجع لواضعي السياسات.

محمد صادق بازرعة( 990 (1): بحوث التسويق للتخطيط والرقابة واتخاذ القرارات"، مكتبة

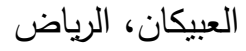

يحيى عبد الرحمن رضا(ي9 (99)): الجوانب القانونية للشركات غير الوطنية، دار النهضة حاتم فارس الطعان( ·. . ץ): الاستثمار أهدافه ودوافعه، كلية الاقتصاد والإدارة، جامعة بغداد.

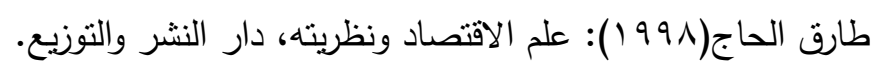

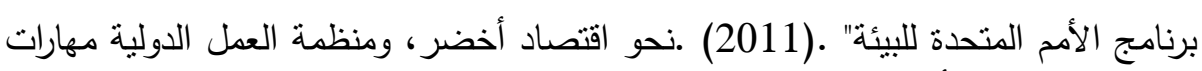
من أجل فرص عمل خضراء :رؤية عالمية"، جنيف. 


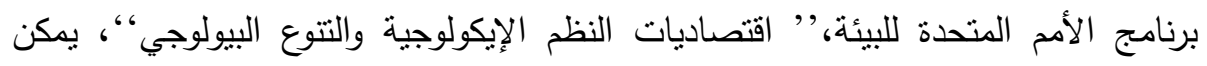

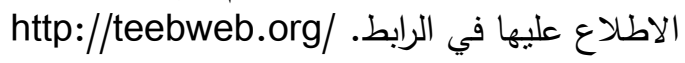
www.eeaa.gov.eg/ar-eg موقع وزارة البيئة الرابط الرطبة http://www.nrea.gov.eg/arabic1.html موقع شركة نقل الكهرباء

Radoslava Kanianska, (2016), "Green Growth and Green Economy", the Cultural and Education Grant Agency.

UNEP, (2017), "Green Foreign Direct Investment in Developing Countries", Federal Ministry for Economic Cooperation and Development,m Germany.

UNEP, (2010), "Green economy developing Countries Success Stories".

OECD, (2012), "Accelerated Depreciation for Environmental Investment.

http://www.investopedia.com/terms/g/green-investing.asp

Janicke, M., (2013), "Green growth": From a growing eco-industry to economic sustainability. Energy Policy 48.

UNEP, (2011), Towards a Green Economy-Pathway to sustainable development and Poverty Eradication.

Richard Schmalensee, (2013). "The Performance of U.S. Wind and Solar Generating Units," NBER Working Papers 19509, National Bureau of Economic Research, Inc.

CCICED, (2011), Development Mechanism and Policy Innovation of China's Green Economy. CCICED Annual General Meeting 2011, Beijing.

Chakraborty, Debashis \& Mukherjee, Sacchidananda, 2010. "Relationship between Trade, Investment and Environment: A Review of Issues," MPRA Paper 23333, University Library of Munich, Germany.

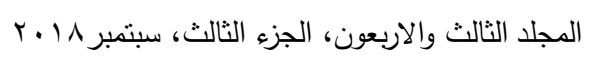


Dunning, J, H., (1988), "The Eclectic Paradigm of International Production: A Restatement and Some Possible Extensions", Journal of International Business Studies, volume 19, issue 1 .

Mehmet ERYİĞİT, (2012), "The long run relationship between foreign direct investments, exports, and gross domestic product: panel data implications," Theoretical and Applied Economics, Asociatia Generala a Economistilor din Romania - AGER, vol. 0(10(575)).

Chakraborty, D., (2012), "Is India turning into a pollution heaven? Evidences from trade".

Matthew A. Cole \& Robert J.R. Elliott \& Toshihiro Okubo, (2010), "Trade, Environmental Regulations and Industrial Mobility: An Industry-Level Study of Japan," Discussion Paper Series DP2010-22, Research Institute for Economics \& Business Administration, Kobe University. Lucas et al., 1992.

Acharyya, J., (2009), "FDI, Growth and the environment: evidence from India on CO emissions during the last two decades", Journal of Economic Development 34.

Michael T. Rock, (2003), "The Politics of Development Policy and Development Policy Reform in New Order Indonesia," William Davidson Institute Working Papers Series 2003632, William Davidson Institute at the University of Michigan.

Costantini, Valeria \&Monni, Salvatore, (2008), "Environment, human development and economic growth," Ecological Economics, Elsevier, vol. 64(4).

Fredriksson et al., (2003), "Effects of Environmental Regulations on Manufacturing Plant Births: Evidence from a Propensity Score Matching Estimator, the Review of Economics and Statistics, MIT pres Journal, Vol. 85, No. 4

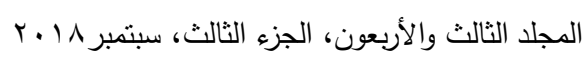


Huberty, Mark, et al. 2011. Shaping the Green Growth Economy. Berkeley, C.A.: Green Growth Leaders (http://www.uncsd2012.org/content/documents/Shapingthe-GreenGrowth-Economy_report.pdf

http://diskussionspapiere.wiwi.uni-hannover.de/pdf_bib/dp-355.pdf http://www.millennium-institute.org/projects/index.html .

Richard Schmalensee, (2012), "From 'Green Growth' to Sound Policies: An Overview,"Energy Economics, vol. 34 (Supplement 1), S2-S6.

\title{
THE IMPACT OF THE APPLICATION OF GREEN POLICIES ON THE FLOW OF DIRECT INVESTMENTS IN EGYPT
}

Diab, A. M. ${ }^{(1)}$ and Mandur, A. F. ${ }^{(2)}$

1) Institute for Environmental Research and Studies, Ain Shams University 2) Faculty of Commerce, Ain Shams University

\begin{abstract}
This study aims at predicting the effect of the application of Green Economy policies in Egypt, as an alternative to the traditional "Business as Usual" policies, and to assess the implications of this transformation on the ability to attract Direct Investment to the Arab Republic of Egypt. The research is limited to the energy sector. The study covers the period from 2001 to 2030, which has been chosen based on Egypt's sustainable development Vision 2030. Some focus has been devoted to the period ending 2020, the date set in February 2008 when the Supreme Council of Energy approved an ambitious plan to increase the share of renewable energy to become $20 \%$ of the energy
\end{abstract}

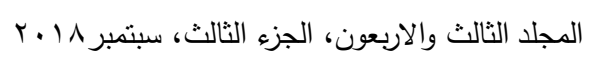




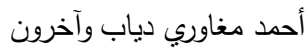

mix by 2020. The research methodology is designed to assess the responsiveness of investor upon the enforcement of Green policy measures relevant to traditional economic policies pertinent to the sector under study.

Emphasis has been given to the Energy sector, given its direct impact on overall economic development, based on the size of the labor force employed in the sector, its contribution to Egypt's gross domestic product and its interconnectivity with almost all economic, environmental and social fields.

In assessing the implications of, the study emphasized the intertwined implications and possible overlap between economic, Environmental and Social indicators. To this end, the study relied on the documented data provided by relevant institutions and from private companies. The research adopted the questionnaires methodology to test the main hypothesis on which the research was based, namely, "There is no significant implication for investors upon the transformation to Green Economy policies that incorporates, economic, environmental and social dimensions". To test this assumption, the research had to break it down into three "Null" sub hypothesis as follows:

1- "There is no significant statistical relation between economic and trade policies and the investment decisions for businessmen."

2- "There is no statistically significant relation between environmental policies and the investment decisions for business people."

3- "There is no statistically significant relation between Social policies and the investment decisions for businessmen."

The research used the SPSS software to test the significant relation between green policies and investment decisions. It has further assessed the policies that would be mostly significant and concluded that transformation to green policy regime is of ultimate importance from economic, social and environmental perspectives, hence has provided some policy recommendations to proceed with in order for the transformation to be effective. Moreover, the research assessed the growth rates on certain economic, environmental and social measurable variables such as, employment, poverty and reduction in $\mathrm{CO} 2$ emissions, after transformation to green policies has been realized. The study has shown that the average increase of the growth rates on the

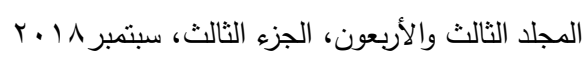


مجلة العلوم البيئية

معهد الدراسات والبحوث البيئية - جامعة عين شمس ليه

assessed variables ranges between 6-15\% depending on the variable assessed. 